\title{
A diluição do jornalismo no ciberjornalismo
}

\author{
HELDER BASTOS \\ Universidade do Porto - Portugal - bastos.helder@gmail.com \\ Jornalista (Escola Superior de Jornalismo), mestre e doutor em \\ Ciências da Comunicação (Universidade Nova de Lisboa)
}

\begin{abstract}
Resumo
O aparecimento da Internet e a subsequente emergência do ciberjornalismo proporcionou ao jornalismo a exploração de novos territórios e diferentes linguagens. Surgiram narrativas inovadoras e práticas inéditas. Nasceram novos géneros. Entre outras potencialidades, o hipertexto, o multimédia, a interatividade, a ubiquidade e a instantaneidade levaram os média noticiosos a reconfigurar-se de modo a responder às exigências do novo meio, às tendências do momento e ao crescimento e sofisticação das audiências online. Os jornalistas não ficaram imunes às transformações provocadas pela adaptação ao ciberespaço. Direta ou indiretamente, foram afetados nas suas práticas, papéis e questionamentos de ordem ética. Nos últimos dezassete anos, o ciberjornalismo foi crescendo, nuns países depressa e de modo assertivo, noutros, como Portugal, mais devagar, com hesitações e pouco sentido de risco. Pelo caminho, o novo ramo do jornalismo foi consagrando um conjunto de modelos, regras e práticas que se começam a normalizar, isto é, a tornar-se num conjunto de normas mais ou menos partilhadas pela tribo ciberjornalística. $O$ que se pode questionar é se esta normalização não tem vindo a afastar o ciberjornalismo de um conjunto de valores, práticas e papéis consagrados ao longo da história da profissão pelos jornalistas um pouco por todo o mundo. Neste ensaio argumenta-se que temos vindo a assistir, em particular em Portugal, a uma gradual diluição de pilares essenciais do jornalismo no ciberjornalismo e, em paralelo, a uma sobrevalorização de aspectos acessórios. Esta diluição tem como principal consequência a perda generalizada da qualidade do jornalismo produzido nas redações digitais.
\end{abstract}

\section{Palavras-chave}

jornalismo, ciberjornalismo, internet, práticas, papéis, ética.

\begin{abstract}
The emergence of the Internet and the subsequent development of online journalism permitted journalism the exploration of new territories and different languages. New narratives and journalistic practices emerged. New genres were born. Among other capabilities, hypertext, multimedia, interactivity, ubiquity and instantaneity led the news media to reconfigure themselves in order to meet the demands of the new medium, trends of the moment and the growth and sophistication of online audiences. Journalists did not stay immune to the changes caused by adaptation to cyberspace. Directly or indirectly, they have been affected in their practices, roles and ethics. In the last seventeen years, online journalism grew, in some countries quickly and
\end{abstract}


Estudos em Jornalismo e Mídia - Vol. 9 NN$^{\circ} 2$ - Julho a Dezembro de 2012 ISSNe 1984-6924

assertively, in others, like Portugal, more slowly, with hesitations and little sense of risk. Along the way, the new branch of journalism developed a set of models, rules and practices that began to normalize and shared by the community of online journalists. What can be questioned is whether this normalization has been moving away online journalism from a set of values, practices and roles established throughout the history of the profession by journalists all over the world. This essay argues that we have been witnessing a gradual dilution, particularly in Portugal, of essential pillars of journalism in the online journalism and, in parallel, the overvaluation of accessory aspects. The main consequence of this dilution is the general loss of quality of journalism produced in digital newsrooms.

\section{Keywords}

journalism, online journalism, internet, practices, roles, ethics.

Artigo recebido em 31/08/2012

Aprovado em 20/09/2012 


\section{Pilares diluídos}

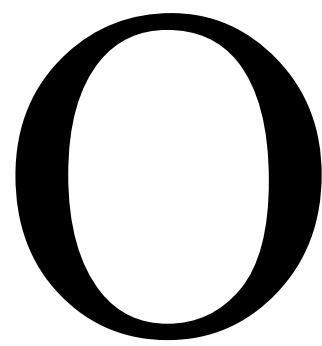

trabalho de produção jornalística própria, isto é, levado a cabo pelo próprio ciberjornalista e assinado por si, estará entre as práticas mais diluídas na transição do jornalismo para o ciberjornalismo. É certo que se trata de uma tendência também observável no jornalismo em geral - em particular na imprensa, que atravessa uma forte crise - mas no ciberjornalismo atinge por vezes proporções extremas. Quando passa a trabalhar numa redacão digital, o jornalista tende a ser enquadrado num conjunto de rotinas de produção, mais de caráter técnico do que propriamente jornalístico, que o afastam da possibilidade de recolher informação pelos seus próprios meios, de seleccioná-la, de redigi-la, de colocá-la em contexto, de preparar os seus textos ou montar as suas peças. Como referem FORTUNATI et al. (2009), de uma perspectiva mais pessimista, a internet introduziu uma nova geração de profissionais dedicados a preparar edições online, muitas vezes jovens e mal pagos. Com deadlines apertados, tendem a concentrar o trabalho em tarefas de copiar e colar em vez de escreverem artigos próprios.

Como efeito negativo colateral, o cultivo de fontes próprias, um processo que exige disponibilidade, tempo e contactos pessoais regulares, vê-se também relegada para segundo plano, quando não esvaziada por completo, face às múltiplas urgências do imediato. Neste cenário, trabalhos de maior fôlego, que por norma exigem grande dispêndio de tempo, como acontece na reportagem de investigação, tornam-se quase uma miragem para o ciberjornalista. A probabilidade de surgir um "furo" jornalístico numa redação digital torna-se sobremaneira reduzida.

Em vez de produção jornalística própria, muitos profissionais - não poucas vezes enquadrados em equipas de serviços mínimos, onde faltam meios humanos, técnicos e financeiros - passam parte substancial do seu tempo laboral a transpor e a adaptar para a Web e outras plataformas conteúdos produzidos por outros (colegas da redação tradicional, das agências de informação ou profissionais dos gabinetes de imprensa), a tratar fotografia ou vídeo, em geral produzidos por outros, a moderar comentários dos utilizadores, a gerir a participação dos seus média nas redes sociais, e até mesmo a resolver problemas técnicos informáticos (SANTOS, 2012; BASTOS, 2011; QUANDT, 2008). É de notar que esta espécie de alienação do jornalista, e consequente 
afastamento das práticas e papéis jornalísticos tradicionais, foi, não apenas tolerada, mas aceite quase como inevitável logo desde o início, quando nasceram as primeiras redações digitais (BASTOS, 2010). Afinal, não havia mais ninguém para executar aquelas tarefas que foram surgindo e impondo-se naturalmente no quotidiano dos ciberjornalistas.

O rigor na verificação dos factos foi outro dos pilares diluídos. Proceder à verificação de factos num ambiente de deadline contínuo, como é aquele que marca o ritmo informativo na Web, torna-se uma tarefa sobremaneira difícil de levar à prática e de rotinizar. Verificar exige proceder a contactos com colegas e fontes, pesquisas documentais, consultas de arquivos, cruzamentos. São tarefas que consomem muito tempo. Ora, também por pressão concorrencial, em que "ganha" aquele que der primeiro, tempo é o que menos dispõe o ciberjornalista, que, como agravante, tem por vezes vários ecrãs abertos em simultâneo no seu monitor a exigir-lhe resposta e ação imediata. O imperativo da instantaneidade, somado às multitarefas, dificilmente propicia as condições necessárias a uma disciplina de verificação eficaz, minando-se desta forma a credibilidade das notícias.

Getting the news first - a longstanding high-stakes competition among traditional news market competitors - has become increasingly worrisome given the real-time speed of Web publishing. Reports can be uploaded to the Web nearly instantly as news unfolds, but often without safeguards such as copy-editing and fact checking. The haste with which many news gatherers post their reports on the Web naturally challenges our confidence in the accuracy and completeness of their coverage. In these cases, the worry is often that competition drives the rate at which one publishes rather than the confidence reporters and editors have in the completeness and accuracy of their stories (SPENCE e QUINN, 2008: 265).

Dar primeiro e confirmar depois tornou-se, nos piores casos, um postulado pernicioso em voga. Acresce que a maior parte do material usado nas secções de notícias de "última hora" é proveniente de agências noticiosas. Em muitos casos, as notícias entram automaticamente nos sites, sem qualquer tratamento. Cria-se, deste modo, dois problemas em simultâneo: o da verificação nula e o da validação cega.

O tradicional papel de gatekeeper, outrora monopólio dos jornalistas, que decidiam, a partir de determinados valores-notícia, aquilo que era noticiado ou não, tem também vindo a sofrer alterações, algumas das quais no sentido da diluição, provocadas pelo ambiente informativo aberto da rede. Talvez nenhuma outra função jornalística 
tenha sido tão claramente desafiada pela Web. Na rede, o jornalista deixou de ser $o$ gatekeeper para ser um gatekeeper entre muitos outros (SINGER, 2007). A entrada em cena de novos actores, desde entidades e empresas não jornalísticas a cidadãos, agora produtores, disseminadores e comentadores de informação, confrontou os jornalistas com a necessidade de reavaliarem as suas rotinas de filtragem e de valorização das notícias. Os ciberjornalistas terão sentido ainda com mais intensidade esta necessidade, quanto mais não seja para atender às características das suas audiências online, que têm a capacidade de, sobretudo através das redes sociais, empolar determinadas notícias, obrigando, por vezes, os ciberjornalistas a uma mudança de atitude em relação à valorização noticiosa das mesmas. Além disso, a possibilidade de acompanhamento em tempo real do comportamento das audiências online leva, em certos casos, a alterações dos valores-notícia, uma vez que se tende a dar mais destaque às notícias que obtém melhor feedback, traduzido em rankings das mais lidas, por parte dos ciberleitores. Por último, a desmultiplicação de sítios e fontes na rede, às quais os utilizadores podem aceder sem barreiras, veio contribuir para um certo esvaziamento do papel de gatekeeper do jornalista. No entanto, este relativo esvaziamento não eliminou este papel, antes o modificou. Nos melhores casos, os ciberjornalistas tiveram a oportunidade de, por um lado, reafirmar uma competência jornalística tradicional, que é a de saber seleccionar informação, e, por outro lado, de desenvolver mapas de navegação e certificação na Web para os leitores. Daí se ter começado dos profissionais como sense-makers, intermediadores, orientadores ou gateopeners, alguém que abre as cancelas aos leitores e indica os melhores sítios para se ir buscar informação fidedigna.

Journalists' ethical obligation becomes helping citizens find and understand information they can trust; journalists in such an environment become not gatekeepers but sense-makers. The emphasis shifts from regulating the quantity of information that enters public discourse to ensuring the quality of at least some of that information (SINGER, 2007: 45).

BRUNS (2005) vai mais longe e considera que o processo de seleção das notícias tem sido alterado pelo gatewatching, em contraste com gatekeeping. $\mathrm{O}$ gatewatching consiste na publicação colaborativa de notícias, em sistema open source, que poderá substituir aquele papel tradicional do jornalista. $\mathrm{O}$ autor sugere que os jornalistas necessitam de se reinventar de modo a tirarem partido da tecnologia da internet, plataforma com potencial comprovado para a notícia multiperspetivada. Tal 
modelo de publicação (open source) significaria uma mudança essencial de papel para as audiências dos média. Bruns chama a estes consumidores de notícias 'produtilizadores' ('produsers'), pois têm agora o poder de tomar parte da produção noticiosa. No modelo open source, os utilizadores são encorajados a manipular o conteúdo na página, um potencial de interatividade que implica mudanças no modelo linear tradicional emissor-mensagem-receptor. Assim, os jornalistas tornar-se-ão monitorizadores do portal de informação que é a Web, fornecendo notícias suficientes para servirem apenas como rampa de lançamento onde as pessoas podem participar com novas informações. Quer para os jornalistas, quer para a audiência, o gatewatching implica alterações significativas nos respetivos papéis.

O ciberjornalismo tem, por outro lado, exacerbado uma tendência já sobremaneira visível no jornalismo tradicional, que é a da crescente sendentarização dos jornalistas, cujas saídas em reportagem para o exterior são cada vez mais esparsas (GOMES, 2012). Se há um forte traço comum entre as redações dos cibermédia um pouco por todo o mundo é o da sedentarização dos ciberjornalistas (BASTOS, 2011; FORTUNATI et al., 2009; SALAVERRÍA, 2005). As saídas em reportagem são, em muitos casos, praticamente nulas. Quase todo o trabalho, da recolha de dados ao contacto com as fontes de informação, é feito à secretária e computador. Ir para o terreno e testemunhar presencialmente o acontecimento tornou-se uma prática rara. As inúmeras nuances, ambientes e imprevistos que certos acontecimentos comportam ficam assim fora do alcance do olhar do repórter.

Os jornalistas que trabalham em média na Internet encontram-se provavelmente entre os que menos contacto directo têm com o exterior. Ocupados quase sempre com simples tarefas de edição, na maioria dos cibermeios actuais o seu trabalho limita-se a reconverter para o suporte digital os conteúdos previamente elaborados por outros para o papel, a rádio ou a televisão. Estes jornalistas "digitais" converteram-se assim em imitações dos antigos redatores de secretária, cuja única competência era processar a informação que outros haviam gerado (SALAVERRÍA, 2005: 62).

O somatório das diluições referidas torna assaz difícil a assunção e o cumprimento, por parte dos ciberjornalistas, de alguns papéis consagrados do jornalismo e que têm a ver com a relação deste com a sociedade: a vigilância dos poderes instituídos, o sentido de participação no debate público e a consciência do papel social do jornalista. 
A vigilância dos poderes instituídos implica, desde logo, que o ciberjornalista tenha uma consciência profissional robusta e uma pro-actividade jornalística forte, ao mesmo tempo que pressupõe disponibilidade de tempo para a investigação em profundidade. Ora, estas condições prévias são muitas vezes sufocadas pelas múltiplas solicitações urgentes do imediato. O ciberjornalista é um profissional sujeito a uma grande dose de dispersão de esforço e de atenção. Além disso, a cristalização de certas rotinas e modos de fazer acabou por levar o ciberjornalismo a não equacionar sequer a necessidade de cumprir este papel ou a considerá-lo inalcançável. Por força das circunstâncias, o papel de watchdog acaba assim secundarizado, nuns casos, e esquecido por completo, noutros.

O mesmo para se compreender a atrofia, quer do sentido de participação no debate público, quer da consciência do papel social do jornalismo em geral e dos (ciber)jornalistas em particular. As prioridades destes profissionais tendem a ser de outra natureza, mais virada para a valorização de factores, que poderíamos designar de curto alcance, relacionados com a instantaneidade, a adaptação e tratamento de conteúdos, a formatação, a distribuição multiplataforma, a monitorização, a concorrência e a produção multimédia.

\section{A diluição da "ideologia do jornalismo"}

Autores como DEUZE (2007) caraterizam o conjunto de valores e papéis partilhados pelos jornalistas como elementos constituintes da "ideologia do jornalismo". Esta "ideologia" tem como sustentáculos principais as noções de serviço público (os jornalistas prestam um serviço público como watchdogs e disseminadores de informação); a objectividade (são imparciais e logo credíveis); a autonomia (são livres e independentes no seu trabalho); a instantaneidade (têm um sentido de instantaneidade, atualidade e velocidade); e a ética (os jornalistas têm um sentido de ética, validação e legitimidade).

Com diferentes níveis de intensidade, estes pilares centrais do jornalismo clássico têm vindo a ser desafiados, quer pela evolução recente do jornalismo, exercido em condições cada vez mais difíceis e complexas, quer pelo ciberjornalismo, que exacerbou algumas tendências, entre as quais, como foi referido, a da diluição da noção de serviço público e do jornalista como vigilante dos poderes instituídos. 
O ideal da objectividade, constituinte clássico da identidade profissional dos jornalistas, também tem atravessado um período de crise e vê-se cada vez mais posto em causa.

The objectivity which characterizes so much journalism in the West, at times reducing it to the anodyne, is being largely abandoned by online journalism, even where quite technical subjects are being addressed. Novel and more subjective voices are being given platforms by a new media whose audiences are not committed to it in the same way that print or broadcast audiences were in the past (HALL, 2001: 87).

Os motivos da erosão da objectividade são vários: aumento da desprofissionalização e do amadorismo nas práticas jornalísticas, ou para-jornalísticas; emprego crescente de "empacotadores de notícias" nas edições online; proliferação de novas fontes de informação duvidosas num ambiente de competição veloz na Web, também entre profissionais e amadores. Por vezes, jornalistas e ciberjornalistas são incentivados a terem "voz", a deixarem de se "esconder" por detrás da aparente neutralidade das notícias, para assim poderem "competir" como as vozes, carregadas de subjectividade, que escrevem nos blogues mais influentes.

Por outro lado, a autonomia dos ciberjornalistas é posta em causa pela crescente precarização das relações laborais nas empresas jornalísticas, mas também pelo facto de aqueles profissionais, a quem se exige que produzam mais em cada vez menos tempo, trabalharem em equipas reduzidas no seio de redações digitais com falta de meios, em especial financeiros, próprios (BASTOS, 2011; DEUZE e MARJORIBANKS, 2009; DOMINGO, 2006; SCOTT, 2005). Com exceção dos cibermédia de raiz, a subordinação das redações digitais às rotinas e conteúdos das "redações-mãe" pode revelar-se igualmente um factor limitativo. Acresce que, em muito casos, a interpenetração, por vezes estimulada pelas hierarquias das empresas, entre ciberjornalismo, marketing e publicidade pode acabar a condicionar a autonomia dos ciberjornalistas.

São, pois, de várias ordens os constrangimentos que interferem no quadro ético e deontológico dos ciberjornalistas. Note-se, a propósito, que o balizamento das suas tarefas e rotinas predominantes pode constituir em si mesmo um entrave, quer à autonomia, quer ao questionamento ético: o profissional debate-se com dilemas éticos sobretudo quando cumpre os seus papéis e práticas tradicionais enquanto jornalista. É pouco provável que de rotinas de empacotamento noticioso, gestão de conteúdos ou 
colagens multimédia nasçam questões ética e deontologicamente pertinentes ou relevantes.

Que os conceitos de velocidade e de instantaneidade sempre estiveram associados ao jornalismo é um facto difícil de contestar. Mas, no ciberjornalismo, em que o deadline é contínuo e a concorrência feroz, a instantaneidade acaba por ser hipervalorizada, sobrepondo-se, por vezes, a outros critérios fundamentais para a qualidade da notícia.

\section{Aspectos sobrevalorizados}

A instantaneidade tornou-se o centro de gravidade do ciberjornalismo. A voracidade dos ciberleitores pelas "últimas notícias", a par da necessidade de não fícar atrás da concorrência, levou os cibermédia a acelerar os ciclos noticiosos com atualizações cada vez mais rápidas, mais curtas e menos intermitentes. Os padrões temporais aceleraram de forma tão drástica que alguns autores falam em "ciclone noticioso" (KLINENBERG, 2005). Nesta aceleração, os riscos multiplicam-se e o preço paga-se, não poucas vezes, em erros crassos e perda de credibilidade. É extensa a lista de esparrelas noticiosas em que caíram reputados média noticiosos internacionais por querem acompanhar, ou mesmo competir, com a instantaneidade viral de fenómenos como o Twitter. A cultura do deadline contínuo foi conquistando terreno e instalou-se em definitivo no ciberjornalismo, acabando por absorver grande parte das energias e tempos de trabalho dos ciberjornalistas. A par de outros factores, a concentração de esforços na instantaneidade cria condições para a diminuição do rigor e o aumento da superficialidade.

As tendências em direç̧ão à velocidade, ao reempacotamento de conteúdos e aos assuntos superficiais facilitados pela Web caricaturam o "jornalismo contextualidado" prometido por proeminentes analistas de novos média. Multimédia, hiperligações, atualizações dinâmicas e interligações com arquivos de material de contexto têm em abstracto um grande potencial, mas acrescentam muito pouco se a lógica por detrás das operações comerciais correr contra a corrente de tais inovações. As melhores hipóteses de diversidade e enriquecimento da esfera pública através da produção de notícias digitais envolvem mais, e não menos, recursos. É por isso que, na base, a convergência de redações é um fenómeno que conduz à homogeneização. Significa menos notícias cobertas por menos jornalistas que chegam a mais canais de média (SCOTT, 2005: 115). 
A instantaneidade implica que o ciberjornalista tenha, ou desenvolva, aptidões de tratamento rápido e contínuo de informação. A par disso, numa redação digital, será tanto mais apreciado quanto mais desenvolvidas forem as suas aptidões multimédia, ou seja, a sua capacidade de trabalhar em simultâneo com vários média (áudio, vídeo, fotografia, texto), dominando as suas linguagens e a própria narrativa hipermédia. Até aqui, nada de preocupante, uma vez que a Web é, por natureza, multimédia e hipertextual. O problema começa quando as aptidões multimédia dos ciberjornalistas, por norma muito valorizadas por quem os contrata, não são acompanhadas de aptidões jornalísticas tradicionais básicas, tais como saber distinguir entre o que é ou não notícia, ter intuição para a descobrir, obter informação em primeira mão, investigar em profundidade e reportar. Este desequilíbrio entre aptidões técnicas de ponta e qualidades jornalísticas tradicionais é muitas vezes acompanhado, e agravado, pela incipiente consciência ética e deontológica de recém-chegados à profissão. Nos piores casos, o resultado é a criação de um profissional híbrido, a meio caminho entre o técnico de empacotamento de notícias multimédia e o jornalista de alcance limitado.

Acresce que vários estudos indicam que o ciberjornalismo aumentou a pressão sobre os ciberjornalistas no atinente à velocidade e ao desempenho de tarefas múltiplas. Os profissionais consideram que o trabalho adicional e as pressões do tempo minam a sua capacidade de concretizar o seu ofício (BASTOS, 2011; CAWLEY, 2008; LAWSON-BORDERS, 2006; KLINENBERG, 2005).

O empenho na forma - em detrimento do investimento na substância, no contexto, na profundidade ou na produção de informação própria e exclusiva - é outro dos aspectos sobrevalorizados no ciberjornalismo. Mais do que a apresentação de notícias ou reportagens bem trabalhadas do ponto de vista jornalístico, tem vindo a privilegiar-se a procura do melhor grafismo, das melhores opções de usabilidade dos sites, de preferência imitando os melhores sites noticiosos internacionais, do melhor efeito visual e narrativo nas (escassas) reportagens multimédia, do último grito em produção Flash, do vídeo de curta duração que complemente o texto da agência, dos ícones ou aplicações da moda visíveis na homepage.

Em paralelo, tem vindo a ganhar força a tendência para a disseminação dos mesmos conteúdos através de múltiplas plataformas e dispositivos. A estratégia da distribuição multiplataforma, no entanto, coloca o acento tónico na forma e eficácia da 
distribuição, na proeza tecnológica, e não tanto na qualidade da informação distribuída. A quantidade na difusão disfarça muitas vezes a falta de diversidade noticiosa e uma homogeneização acentuada dos "conteúdos", palavra em voga de significado amplo que tem servido para diluir a produção dos jornalistas na que tem origem em áreas tão diversas como a publicidade, o marketing ou mesmo o entretenimento.

Por último, seguir as últimas tendências da Web tornou-se um imperativo nos cibermédia. Das redes sociais às aplicações (vulgo apps), dos blogues e do "jornalismo do cidadão" às versões para iPad e iPhone, as empresas de média procuram não perder o alucinante ritmo do ciberespaço. Pelo meio, tentam, não sem algum grau de ansiedade, encontrar o modelo de negócio que lhes permita compensar, sobretudo no caso dos jornais, a perda de leitores e de anunciantes no papel. A adesão entusiástica às novas tecnologias parece ter como principal combustível a crença na salvação futura do negócio das notícias, mas, em geral, não é acompanhada pela concepção de estratégias de fundo.

A diluição de pilares centrais da actividade jornalística no ciberjornalismo teve como principal consequência a perda generalizada da qualidade do jornalismo produzido nas redações digitais. Quando boa parte do tempo laboral e das energias dos profissionais é dirigido para tarefas de alto teor técnico de rotina e baixa densidade jornalística, não se poderia esperar que aquelas redações fossem um centro de produção permanente de notícias em primeira mão, de reportagens no terreno ou de trabalhos de investigação em profundidade.

Este processo de afastamento de práticas e papéis tradicionais do jornalismo e a assunção de novas práticas e de novos e diferentes papéis acabou por provocar uma diluição da própria identidade profissional dos jornalistas da Web. A pergunta é feita, umas vezes pelos próprios, outras vezes por vozes críticas exteriores às redações: o que fazem no dia-a-dia (alimentação de fluxos contínuos de última hora, adaptação de conteúdos, copy/paste, moderação de comentários, edição multimédia, gestão de redes sociais, etc.) é jornalismo? A pergunta acompanha o ciberjornalismo desde o seu dealbar (BASTOS, 2010; BASTOS, 2000) e, na prática, conduziu ao avolumar de preconceitos em relação ao novo ramo do jornalismo nascido com a internet. Os próprios ciberjornalistas queixam-se de o seu trabalho não ser devidamente valorizado, quer pelos seus pares das redações tradicionais, quer pelas empresas jornalísticas, quer ainda 
por instituições e organizações exteriores ao jornalismo. O ciberjornalismo tende a ser visto, tanto interna como externamente, como jornalismo de segunda categoria, algo que acaba por se refletir de forma negativa na autoestima de quem nele trabalha.

\section{Razões para a diluição}

Como explicar a aparente erosão de práticas e valores tradicionais do jornalismo na transição para o ciberjornalismo? A explicação passa por uma conjugação ampla de factores, que aqui podemos apenas esboçar, ligados sobretudo à natureza dos novos média, às empresas jornalísticas, nomeadamente as portuguesas, aos modelos de negócio e aos próprios jornalistas.

No cômputo geral, as empresas parecem nunca ter tido uma percepção clara da internet e das suas implicações e, menos ainda, das estratégias a adotar consoante as circunstâncias e o momento histórico. Não poucas vezes acusadas de conservadorismo e falta de arrojo, revelaram, salvo algumas exceções, dificuldades em entender a rede mundial, as suas modalidades comunicacionais, os seus espaços, tribos e culturas, mas também o que era suposto estimular em termos de jornalismo na Web, algo que dificultou o posicionamento e a otimização dos média online. Daí as inúmeras hesitações, em particular quando se fala na necessidade de investir. A estratégia predominante foi, pois, a de navegar à vista. As empresas mantiveram, quase sempre, reduzido ao mínimo o contingente das redações digitais, constituídas, em geral, por profissionais pouco experientes e, em não poucos casos, precários em termos de vínculo contratual. O comportamento hesitante da generalidade das empresas jornalísticas é indissociável da questão do modelo de negócio, ou seja, do facto de não terem encontrado formas de rentabilizar o investimento nas edições Web. Em suma, o enquadramento empresarial dos ciberjornalistas foi-lhes sobremaneira desfavorável e criou as condições para uma certa atrofia profissional.

Os ciberjornalistas, por sua vez, viram-se muitas vezes incompreendidos, com dúvidas sobre quais eram, ou deveriam ser, os seus papéis. Confrontados com novos dilemas éticos e deontológicos, sem formação específica para o exercício cabal do ciberjornalismo - em particular no que às competências multimédia diz respeito - e inseridos em equipas reduzidas, foram desde cedo colocados perante a exigência de produzir cada vez mais em quantidade e instantaneidade. O preço a pagar foi o declínio 
da qualidade e da profundidade. Poder-se-ia também argumentar que acabaram por desenvolver uma espécie de subcultura profissional própria, mais em linha com certos traços da cibercultura, em que se valoriza sobretudo a instantaneidade, a partilha, o multimédia, a mobilidade (em termos de acesso e dispositivos), a monitorização permanente do comportamento das audiências. Assinale-se aqui o paradoxo: apesar de quererem saber ao minuto a adesão dos leitores a esta ou aquela notícia, parecem, no entanto, investir pouco tempo e esforço na interatividade com os leitores/utilizadores, que são uma parte importante a ter em conta quando se quer compreender o modo como trabalham os jornalistas (BASTOS, 2011; DOMINGO, 2008).

A agravar estes factores, a quase completa ausência de formação profissional dos ciberjornalistas, fosse providenciada pelas empresas, fosse procurada no exterior, em escolas ou universidades, pelos próprios profissionais. Entre jornalistas e ciberjornalistas, poucos foram os que puderam beneficiar de formação que os preparasse melhor para enfrentar os desafios colocados pela vertiginosa aceleração provocada pela expansão da internet e a chegada dos paradigmas da convergência.

\section{Perguntas para o futuro}

O caminho traçado pelo ciberjornalismo ao longo dos anos e o rumo que parece estar a tomar suscitam inúmeras interrogações. A primeira: como será o jornalismo se e quando todos os jornalistas produzirem para todas as plataformas e acabar por se diluir por completo a distinção entre jornalismo e ciberjornalismo?

A aposta de muitos grupos de média na convergência, que tem, nos últimos anos, passado pela integração de redações e cruzamentos de conteúdos multimédia, torna possível antecipar um cenário de convergência total: tecnológica, empresarial, profissional e de conteúdos. Se aí chegarmos, que restará do jornalismo da era préinternet? Terá passado em definitivo à história? Perguntado de outro modo: terá então o jornalismo clássico sido diluído por completo nos paradigmas em construção do ciberjornalismo? Investigar, cultivar fontes próprias, dar notícias em primeira mão, dar voz a grupos sociais, contextualizar, reportar, vigiar os poderes instituídos - de modo a, na síntese de KOVACH e ROSENSTIEL (2005), “dar aos cidadãos a informação de que necessitam para serem livres e autogovernarem-se" - serão considerados papéis 
Estudos em Jornalismo e Mídia - Vol. $9 \mathrm{~N}^{\circ} 2$ - Julho a Dezembro de 2012

ultrapassados e práticas anacrónicas, incompatíveis com a "hipermodernidade" jornalística?

O jornalismo encontra-se numa encruzilhada importante na sua história. A via da velocidade e da superficialidade, para não falar da espectacularidade ou da leviandade, conquista terreno todos os dias. O novo ambiente mediático e jornalístico a isso é cada vez mais propício. A Web e outras plataformas impulsionam novos modos de estar e de fazer nas redações. Como em todas as grandes mudanças, algo se perde e algo se ganha. Mas o jornalismo de referência, assente em standards de qualidade, parece estar a sair vencido. Há mesmo quem vaticine o "fim do jornalismo tal como o conhecemos". A questão é que este jornalismo continua a ser indispensável a um funcionamento saudável das sociedades democráticas. Donde, se o jornalismo "tal como o conhecemos" se tornar irreconhecível, talvez seja de arranjar um novo nome para o ofício que lhe suceder.

Resta saber se o jornalismo e os jornalistas conscientes do seu importante papel social estão interessados em reafirmar os seus valores de sempre ou vão, por falta de força, vontade ou alternativas, assistir à crescente diluição da sua razão se ser.

\section{Bibliografia}

BASTOS, H. Ciberjornalistas em Portugal: Práticas, Papéis e Ética. Lisboa: Livros Horizonte, 2011. BASTOS, H. Origens e Evolução do Ciberjornalismo em Portugal: Os Primeiros Quinze Anos (1995-2010). Porto: Edições Afrontamento, 2010.

BASTOS, H. Jornalismo Electrónico: Internet e Reconfiguração de Práticas nas Redacções. Coimbra: Minerva, 2000.

BRUNS, A. Gatewatching: Collaborative Online News Production. New York: Peter Lang, 2005.

CAWLEY, A. News Production in an Irish Online Newsroom: Practice, Process and Culture, in C. A. Paterson and D. Domingo (eds) Making Online News: The Ethnography of New Media Production, pp. 45-60. New York: Peter Lang, 2008.

DEUZE, M.; MARJORIBANKS, T. Newswork, Journalism, 10: 555-561, 2009.

DEUZE, M. Media Work. Cambridge: Polity Press, 2007.

DOMINGO, D. Interactivity in the Daily Routines of Online Newsrooms: Dealing with an Unconfortable Myth, Journal of Computer-Mediated Communication, 13(3): 680-704), 2008.

DOMINGO, D. Inventing Online Journalism. (Tese de Doutoramento) - Departament de Periodisme i Ciències de la Comunicació. Barcelona: Universitat Autònoma de Barcelona, 2006.

FORTUNATI, L.; SARRICA, M.; O'SULLIVAN, J.; BALCYTIENE, A.; HARRO-LOIT, H.; MACGREGOR, P.; ROUSSOU, N.; SALAVERRÍA, R.; LUCA, F.. 'The influence of the internet on european journalism', Journal of Computer-Mediated Communication, 2009, 14(4): 928-963.

GOMES, R. A queda da reportagem e os contributos da Internet para o sedentarismo da prática jornalística. (Tese de Doutoramento) - Departamento de Ciências da Comunicação. Lisboa: Universidade Nova de Lisboa, 2012. 
HALL, J. Online Journalism: A Critical Primer. London: Pluto Press, 2001.

KLINENBERG, E. Convergence News Production in a Digital Age, Annals of the American Academy of Political and Social Science, 597(1): 48-64, 2005.

KOVACH, B.; ROSENSTIEL, T. Os Elementos do Jornalismo. Porto: Porto Editora, 2005.

LAWSON-BORDERS, G. Media Organizations and Convergence: Case Studies of Media Convergence Pioneers. Mahwah, NJ: Lawrence Erlbaum Associates, 2006.

QUANDT, T. News tuning and content management: An observation study of old and new routines in German online newsrooms, in C. A. Paterson and D. Domingo (eds) Making Online News: The Ethnography of New Media Production, pp. 45-60. New York: Peter Lang, 2008.

SALAVERRÍA, R. (coord.). Cibermedios: El impacto de internet en los medios de comunicación en Espanha. Sevilla: Comunicación Social Ediciones y Publicaciones, 2005.

SANTOS, L. Journalism in transition - A study of Change at Jornal de Notícias's online newsroom. (Tese de Doutoramento) - Departamento de Ciências da Comunicação. Braga: Universidade do Minho, 2012.

SCOTT, B. A Contemporary History of Digital Journalism, Television \& New Media, Vol. 6 No. 1, Februar, 89-126, 2005.

SINGER, J.; FRIEND, C. Online Journalism Ethics: Traditions and Transitions. New York: M. E. Sharpe, 2007.

SPENCE, E.; QUINN, A. Information Ethics as a Guide for New Media, Journal of Mass Media Ethics, 23:264-279, 2008.

Este artigo e todo o conteúdo da Estudos em Jornalismo e Mídia estão disponíveis em http://www.periodicos.ufsc.br/index.php/jornalismo/index

Estudos em Jornalismo e Mídia está sob a Licença Creative Commons. 